The Journal of Animal \& Plant Sciences, 30(3): 2020, Page: 586-594

ISSN (print): 1018-7081; ISSN (online): 2309-8694

\title{
PHYLOGENETIC ANALYSIS OF SHEEP POX AND GOAT POX VIRUS STRAINS IN SAUDI ARABIA
}

\author{
Ibrahim M. El-Sabagh ${ }^{1,2}$; Ahmed M. Al-Ali ${ }^{1}$; Mohamed A. Salem ${ }^{3,4,5}$; Hussein A. Al-Wsaibei ${ }^{5}$; Abdallah M. Al- \\ Butayan ${ }^{5}$ and Fahdel M. Housawi ${ }^{3}$
}

\begin{abstract}
${ }^{1}$ Central Biotechnology Laboratory, College of Veterinary Medicine, King Faisal University, P.O. Box: 400 Al-Ahsa, 31982, Saudi Arabia; ${ }^{2}$ Department of Virology, Faculty of Veterinary Medicine, Cairo University, 12211, Giza, Egypt. ${ }^{3}$ Department Clinical Sciences, College of Veterinary Medicine, King Faisal University, P.O. Box: 400 Al-Ahsa, 31982, Saudi Arabia.; ${ }^{4}$ Department of Medicine and Infectious Diseases, Faculty of Veterinary Medicine, Cairo University, 12211, Giza, Egypt.; ${ }^{5}$ Veterinary Teaching Hospital, College of Veterinary Medicine, King Faisal University, P.O. Box: 400 Al-Ahsa, 31982, Saudi Arabia.

Corresponding Author’s E-mail : ibsabagh@kfu.edu.sa and ibrahimelsabagh@yahoo.com
\end{abstract}

\begin{abstract}
Sheep pox virus (SPPV) and goat pox virus (GTPV) are classified as causing notifiable viral diseases. They belong to the genus Capripoxvirus (CaPV) along with the lumpy skin disease virus (LSDV). CaPVs are mainly host-specific, but there are frequent cross-species infections. Six strains of CaPVs were identified in outbreaks of sheep pox and goat pox in Saudi Arabia between 2013 and 2017. We investigated the sequencing features and phylogenetic analyses of the P32, PRO30 and GPCR genes of the detected SPPVs and GTPV to expose their genetic relationship. Sequence analysis revealed that the percentage of nucleotide identity of P32, PRO30 and GPCR ranged from $94 \%$ to $99 \%, 93 \%$ to $100 \%$ and $90 \%$ to $99 \%$, respectively, with other worldwide isolates of CaPVs. The three constructed phylogenetic trees classified the six detected CaPVs into five SPPVs and one GTPV. This study is the first to investigate the genetic relatedness among SPPVs and GTPVs based on full-nucleotide sequences of the P32, PRO30 and GPCR genes. Multiple genetic sequencing analyses and alignments will greatly improve the accuracy of the diagnosis, epidemiologic knowledge and control of CaPV diseases in Saudi Arabia.
\end{abstract}

Keywords: Capripoxviruses; GPCR, P32 and PRO30 genes; phylogenetic analysis; Saudi Arabia; sequencing https://doi.org/10.36899/JAPS.2020.3.0069 Published online March 25, 2020

\section{INTRODUCTION}

SPPV, GTPV and LSDV make up the genus Capripoxvirus of the Chordopoxvirinae subfamily of the Poxviridae family (Bhanot et al., 2009). They are enveloped dsDNA viruses. The viral genome is approximately $150 \mathrm{Kbps}$; it contains a coding region in its center and on its edges with two inverted repeats that are identical in sequence, which is considered a unique composition for poxviruses. The genomic identities of the genus Capripoxvirus reach $96 \%$ between species and 99\% between strains of the same species (Tulman et al., 2002). SPPV and GTPV cause notifiable viral diseases that are endemic in the Middle East, Central and North Africa, India, China, Vietnam, Chinese Taipei, Turkey and other regions north of the equator (OIE, 2010). They are a major limitation to the establishment of exotic breeds of sheep and goats and to the improvement of the intensive production of livestock (Zheng et al., 2007). The morbidity rates can reach $80 \%$ and the mortality rates can approach $50 \%$. In young calves under 1 month of age, morbidity and mortality rates may approach $100 \%$ and $95 \%$, respectively (Beard et al., 2010).
CaPVs are mainly host-specific. They may set up frequent cross-species barriers among sheep and goats (Bhanot et al., 2009). Most SPPV strains are specific to sheep and most GTPV strains are specific to goats, but some of the strains can infect both sheep and goats (Babiuk et al., 2009). SPPV and GTPV strains are serologically indistinguishable and very closely related (Heine et al., 1999). The diagnosis of SPPV and GTPV mainly depends on clinical signs and serological assays. Infected animals with SPPV or GTPV exhibit fever from 1 to 5 days, followed by the typical skin lesions that originate as erythematous macules and then progress to hard papules (Heine et al., 1999). The center of each papule appears depressed, is white-gray in color, and is necrotic and surrounded by a hyperemic area. Scabs form over the necrotic areas (Abu-Elzein et al., 2003; Bhanuprakash et al., 2006; Rao \& Bandyopadhyay, 2000). The conventional serological assays cannot differentiate between SPPV and GPPV. Characterization of these viruses necessitates molecular identification, sequencing and phylogenetic tree analysis (Beard et al., 2010; Su et al., 2015; Yan et al., 2012; Zhou et al., 2012). 
P32, GPCR and PRO30 are important genes in CaPVs. Sequencing data of these genes are mainly used for distinguishing SPPV and GTPV and presenting the genetic relationship between diverse virus isolates (Cao et al., 1995; Hosamani et al., 2004; Lamien et al., 2011a). The P32 gene corresponds to an envelope protein on the surface membrane of the intracellular viral particle and is homologous to the P35 protein of the vaccinia virus $H 3 L$ gene (Tulman et al., 2002). SPPV and GTPV can be distinguished by a sequencing comparison of the P32 gene on the basis of size (Tian et al., 2010). The GPCR gene translates to the G-protein-coupled chemokine receptor (Cao et al., 1995) and has been used for the differential diagnosis of SPPV, GTPV and LSDV (Lamien et al., 2011b; Le Goff et al., 2009). The PRO30 gene is a homolog of the vaccinia virus $E 4 L$ gene and carries information on the $30-\mathrm{KDa}$, DNA-dependent, RNA polymerase subunit (Tulman et al., 2002). Although the PRO30 gene is conserved between CaPVs, it is used to distinguish SPPVs, GTPVs and LSDVs (Lamien et al., 2011a; Su et al., 2015; Yan et al., 2012; Zhou et al., 2012).

In Saudi Arabia, unfortunately, the information about the current status of $\mathrm{CaPV}$ infections of sheep and goats is very scanty. Abu-Elzein et al. (2003) reported the first isolation and antigenic characterization of a virulent field CaPV from diseased goats. Two outbreaks of sheep pox disease were described in Al-Hassa of the Eastern Province of Saudi Arabia during 2013 and 2014. The causative agent was identified clinically, histopathologically and molecularly by a multiplex polymerase chain reaction (PCR). Partial sequencing of the P32 gene followed by phylogenetic tree analysis revealed that the identified agent was clustered in SPPVs from India and China (Al-Shabebi et al., 2014; Hamouda el al., 2017). Therefore, we used the P32, PRO30 and $G P C R$ genes as molecular biomarkers for the construction of phylogenetic trees for the Saudi Arabian SPPVs and GTPV and various worldwide CaPVs to elucidate the genetic relatedness of these viruses.

\section{MATERIALS AND METHODS}

Samples: Papules and/or crusted scabs were collected from animals on six different farms in the Al-Hassa Governorate in the Eastern Province of Saudi Arabia. The animals were separately reared, unvaccinated sheep and goats. Tissue samples of SPPV/Saudi Arabia 1/2014, SPPV/Saudi Arabia 3/2013, SPPV/Saudi Arabia 4/2017, SPPV/Saudi Arabia 5/2016 and SPPV/Saudi Arabia $6 / 2016$ were collected from diseased sheep on 20 February 2014 from the Al-Goibah region, 15 February 2013 from the Al-Hulaylah region, 10 April 2017 from the Al-Hufof region, 12 December 2016 from the AlGarn region and 12 December 2016 from the Al-Goibah region, respectively. Tissue samples of GTPV/Saudi
Arabia 2/2017 were collected from diseased goats on 13 April 2017 from the Al-Hufof region (Fig 1). The morbidity and mortality rates were $60 \%$ to $80 \%$ and $25 \%$ to $40 \%$, respectively. Samples were transferred in sterile cups to the Central Biotechnology Laboratory at the College of Veterinary Medicine, King Faisal University, Saudi Arabia, and stored at $-20^{\circ} \mathrm{C}$ until used.

DNA extraction: According to the manufacturer's instructions, the total DNA was extracted from tissue samples of up to $25 \mathrm{mg}$ and commercial live attenuated sheep pox virus as a positive control. Deionized water was used as a negative control (DNeasy Blood and Tissue Kit, Qiagen, USA). After complete lysis of the specimens by ATL buffer and proteinase $\mathrm{K}$, absolute ethanol was added, and the mixture was transferred to a spin column. Purified DNA was recovered in $150 \mu \mathrm{l}$ of AE buffer and stored at $-80^{\circ} \mathrm{C}$ for further testing.

Oligonucleotide Primers: The primers used for identification of the CaPVs and sequencing of the P32, $P R O 30$ and GPCR genes were analyzed by the OligoAnalyzer 3.1 (Integrated DNA Technologies, USA) and synthesized by Metabion International $A G$ (Germany). The complete data for the primers are shown in Table 1.

Identification of Capripoxviruses by PCR: The extracted DNAs were screened for identification of CaPVs by multiplex PCR. Briefly, a 2- $\mu 1$ sample of each purified genomic DNA was amplified in $20 \mu \mathrm{l}$ of the final volume of a 2X HotStart Taq Plus Master Mix (Qiagen, USA) containing $1.5 \mathrm{mM}$ of $\mathrm{MgCl}_{2}, 200 \mu \mathrm{M}$ of each dNTP, 1 unit of HotStart Taq Plus DNA polymerase and $10 \mu \mathrm{M}$ of the KS-1.5/KS-1.6 and InS-1.1/InS-1.1 primers. The thermocycling conditions were $95^{\circ} \mathrm{C}$ for 5 minutes for enzyme activation and initial denaturation, followed by 35 cycles at $94^{\circ} \mathrm{C}$ for 30 seconds, $43^{\circ} \mathrm{C}$ for 30 seconds and $72^{\circ} \mathrm{C}$ for 30 seconds, plus a final extension step at $72^{\circ} \mathrm{C}$ for 10 minutes. The amplified products were electrophoresed in $1.2 \%$ agarose gel stained with ethidium bromide and documented using the ultraviolet gel documentation system (Bio-Rad Laboratories, USA).

Sequencing of the P32, PRO30 and GPCR genes: The previously extracted viral DNAs were used to amplify the $P 32$ gene, $P R O 30$ gene and GPCR gene. The $20-\mu 1$ total volume of the PCR reaction contained $2 \mu \mathrm{l}$ of each purified genomic DNA, $10 \mu 1$ of a $2 \mathrm{X}$ HotStart Taq Plus Master Mix (Qiagen, USA) containing $1.5 \mathrm{mM}$ of $\mathrm{MgCl}_{2}$, $200 \mu \mathrm{M}$ of each dNTP and 1 unit of HotStart Taq Plus DNA polymerase, $1 \mu \mathrm{l}(10 \mu \mathrm{M})$ of each forward and reverse primer, $2 \mu \mathrm{l}$ of $\mathrm{MgCl}_{2}(25 \mathrm{mM})$ and $4 \mu \mathrm{l}$ of nuclease-free water. The thermal cycling parameters were $95^{\circ} \mathrm{C}$ for 5 minutes for enzyme activation and initial denaturation, followed by 35 cycles of $94^{\circ} \mathrm{C}$ for 30 seconds; the primers were annealing for 30 seconds 
(Table 1) and at $72^{\circ} \mathrm{C}$ for 120 seconds, and a final extension step took place at $72^{\circ} \mathrm{C}$ for 10 minutes. The amplified products were electrophoresed in $1.2 \%$ agarose gel stained with ethidium bromide and documented using the ultraviolet gel documentation system (Bio-Rad Laboratories, USA). The specific PCR products were extracted from the agarose gel, purified using the Montàge DNA gel extraction kit (Millipore, USA) and sequenced in an automated ABI 3730 DNA sequencer (Applied Biosystems, USA).

Phylogenetic analysis: The obtained sequences of the $P 32, P R O 30$ and GPCR genes were aligned with the $\mathrm{CaPV}$ sequences available in the GenBank database (Table 2) using the online BLAST web tool from the National Center for Biotechnology Information. Multiple alignments of these sequences with the ClustalW method were carried out by MEGA 5.2 technology, and then the phylogenetic analysis was performed. Phylogenetic trees were constructed using the neighbor-joining method, and the reliability of the trees was tested by bootstrapping them with 1000 replicates.

GenBank accession number: The obtained $P 32, P R O 30$ and GPCR gene sequences were submitted to the GenBank database as shown in Table 2.

\section{RESULTS}

Detection of samples suspicious for CaPV: Suspicious papules and/or crusted scabs collected from animals on six different sheep and goat farms were found to be positive for viral DNAs by multiplex PCR. Expected amplicons of approximately 149-bp and 289-bp individual sharp bands were obtained by gel electrophoresis for all tested samples.

Sequence analysis of P32, PRO30 and GPCR genes: The complete open reading frames based on GenBank accession number MN072630 of the P32 (64685-65656), PRO30 (27203-28474) and GPCR (6852-8391) genes of six CaPV (five SPPV and one GTPV) strains were sequenced and subjected to identity analysis. The nucleotide identity of the six P32, PRO30 and GPCR genes shared very close relationships with worldwide CaPVs reported in the GenBank. The nucleotide identity percentage of P32, PRO30 and GPCR ranged from 94\% to $99 \%, 93 \%$ to $100 \%$ and $90 \%$ to $99 \%$, respectively, with other CaPVs isolated from different regions. The nucleotide identity percentage of P32, PRO30 and GPCR ranged from $99.4 \%$ to $100 \%, 97.6 \%$ to $99.6 \%$ and $91.5 \%$ to $99.7 \%$, respectively, within the five Saudi Arabia SPPVs.

Phylogenetic analysis: The three constructed phylogenetic trees support the classification of $\mathrm{CaPVs}$ into three main lineages: SPPV, GTPV and LSDV (Figs 2, 3 and 4). SPPV/Saudi Arabia 1/2014, SPPV/Saudi Arabia 3/2013, SPPV/Saudi Arabia 4/2017, SPPV/Saudi Arabia 5/2016 and SPPV/Saudi Arabia 6/2016 were clustered with other SPPVs, whereas GTPV/Saudi Arabia 2/2017 was clustered with the GTPVs. Phylogenetic analysis of the $P 32$ gene revealed that the GTPV lineage could be divided into three subgroups, whereas all of the SPPVs formed a single cluster. The five Saudi Arabia SPPVs were clustered together with SPPVs from Russia, China and India, whereas the Saudi Arabia GTPV was clustered with the GTPV isolated from Yemen. Analysis of the PRO30 gene phylogenetic tree showed that the investigated SPPVs and GTPVs could be divided into two subgroups. SPPV Saudi Arabia 3/2013 was clustered with the GTPV Saudi Arabia isolated during 1993 and with SPPVs from Turkey and China, whereas SPPV Saudi Arabia 1/2014, SPPV Saudi Arabia 4/2017, SPPV Saudi Arabia 5/2016 and SPPV Saudi Arabia 6/2016 were clustered with SPPVs from Senegal, Tunisia, Morocco, Nigeria, Algeria, Niger and India. GTPV Saudi Arabia 2/2017 was clustered with the GTPV from Iraq. Analyzing the GPCR gene phylogenetic tree revealed that SPPV Saudi Arabia 3/2013, SPPV Saudi Arabia 1/2014, SPPV Saudi Arabia 4/2017, SPPV Saudi Arabia 5/2016 and SPPV Saudi Arabia 6/2016 formed two separate subclusters within the SPPV lineage.

Table 1. Oligonucleotide primes used for identification and sequencing.

\begin{tabular}{|c|c|c|c|c|c|}
\hline Target gene & $\begin{array}{l}\text { Primes } \\
\text { name }\end{array}$ & Sequence $\left(5^{\prime}-3^{\prime}\right)$ & $\begin{array}{l}\text { Annealing } \\
\text { Temp. }\end{array}$ & $\begin{array}{l}\text { Amplicons } \\
\text { size }\end{array}$ & Reference \\
\hline KS-1 DNA & KS-1.5 & 5'-GTGTGACTTTCCTGCCGAAT-3' & & & \\
\hline fragment & KS-1.6 & 5'-TCTATTTTATTTCGTATATC-3' & $43^{\circ} \mathrm{C}$ & $149 \mathrm{bp}$ & Mangana- \\
\hline $\begin{array}{l}\text { Inverted terminal } \\
\text { repeats (ITRs) }\end{array}$ & $\begin{array}{l}\text { InS-1.1 } \\
\text { InS-1.1 }\end{array}$ & 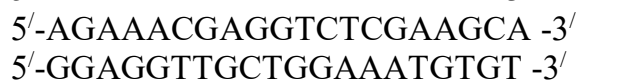 & $43^{\circ} \mathrm{C}$ & $289 \mathrm{bp}$ & $\begin{array}{l}\text { ougiouka } \\
\text { et al. } 2000\end{array}$ \\
\hline P32 gene & $\begin{array}{l}\text { P32-F } \\
\text { P32-R }\end{array}$ & $\begin{array}{l}\text { 5'-ATGGCAGATATCCCATT-3' } \\
\text { 5'-TTACCACAGGCTATTAGAAG-3' }^{\prime}\end{array}$ & $49^{\circ} \mathrm{C}$ & $1181 \mathrm{bp}$ & \\
\hline PRO30 gene & $\begin{array}{l}\text { PRO30-F } \\
\text { PRO30-R }\end{array}$ & $\begin{array}{l}\text { 5/-CTCTGTTCCAAACTAAATCAT-3' } \\
5^{\prime} \text {-TTTTTGTATTACCAATTTCTG-3' }\end{array}$ & $47^{\circ} \mathrm{C}$ & $1385 \mathrm{bp}$ & $\begin{array}{l}\text { Zhou et al. } \\
\quad 2012\end{array}$ \\
\hline GPCRgene & $\begin{array}{l}\text { GPCR-F } \\
\text { GPCR-R }\end{array}$ & $\begin{array}{l}\text { 5'-TTTATCAGCACTAGGTCATTATCT-3' } \\
\text { 5'-TATCACTCCCTTCCATTTTTAT-3' }\end{array}$ & $47^{\circ} \mathrm{C}$ & $1684 \mathrm{bp}$ & \\
\hline
\end{tabular}


Table 2. Capripoxviruses used in the study.

\begin{tabular}{|c|c|c|c|c|c|c|}
\hline \multicolumn{3}{|c|}{ Accession numbers } & \multirow{2}{*}{ Species } & \multirow{2}{*}{ Strain } & \multirow{2}{*}{$\begin{array}{c}\text { Collection } \\
\text { date }\end{array}$} & \multirow{2}{*}{ Country } \\
\hline P32 & PRO30 & GPCR & & & & \\
\hline MG232382 & MG232376 & MG232388 & SPPV & SPPV/Saudi Arabia1/2014 & 2014 & Saudi Arabia \\
\hline MG232383 & MG232377 & MG232389 & GTPV & GTPV/Saudi Arabia2/2017 & 2017 & Saudi Arabia \\
\hline MG232384 & MG232378 & MG232390 & SPPV & SPPV/Saudi Arabia3/2013 & 2013 & Saudi Arabia \\
\hline MG232385 & MG232379 & MG232391 & SPPV & SPPV/Saudi Arabia4/2017 & 2017 & Saudi Arabia \\
\hline MG232386 & MG232380 & MG232392 & SPPV & SPPV/Saudi Arabia5/2016 & 2016 & Saudi Arabia \\
\hline \multirow[t]{3}{*}{ MG232387 } & MG232381 & MG232393 & SPPV & SPPV/Saudi Arabia6/2016 & 2016 & Saudi Arabia \\
\hline & GU119925 & FJ869360 & GTPV & Saudi Arabia/93 & 1993 & Saudi Arabia \\
\hline & Gu119916 & FJ869383 & SPPV & Turkey/98 Van2 & 1998 & Turkey \\
\hline \multirow[t]{11}{*}{ KF991005 } & KF991004 & & SPPV & Jilin & NI & China \\
\hline & JQ310671 & & SPPV & SPPV/GanS/2/2011 & 2011 & China \\
\hline & GU119926 & FJ869380 & SPPV & Sangalcam $/ 88$ & 1988 & Senegal \\
\hline & KT964234 & & SPPV & Tunisia 14/15 & 2015 & Tunisia \\
\hline & GU119929 & FJ869378 & SPPV & SPPV11 & NI & Morocco \\
\hline & KF495220 & & SPPV & Ranipet P-55 & NI & India \\
\hline & GU119928 & & GTPV & Nigeria/99 & 1999 & Nigeria \\
\hline & GU119920 & FJ869385 & SPPV & Algeria/93 & 1993 & Algeria \\
\hline & GU119922 & & SPPV & Niger/88 & 1988 & Niger \\
\hline & GU119930 & & GTPV & VC6 & NI & Chad \\
\hline & GU119939 & & GTPV & Burkina Benogo 3A & NI & Burkina Faso \\
\hline \multirow[t]{6}{*}{ EU625262 } & GU119927 & FJ869362 & GTPV & Sana`a/1983 & 1983 & Yemen \\
\hline & GU119942 & FJ869357 & GTPV & Iraq/61 Gorgan & 1961 & Iraq \\
\hline & GU119933 & & GTPV & $\mathrm{Oman} / 84$ & 1984 & Oman \\
\hline & GU119943 & & LSDV & RSA/08M143/08 & 2008 & South Africa \\
\hline & KJ818288 & KJ818281 & LSDV & SGP O-240 & NI & Kenya \\
\hline & GU119944 & & LSDV & Sudan/99 Atbara & 1999 & Sudan \\
\hline KJ679574 & & & SPPV & $\mathrm{RF}$ & 2012 & India \\
\hline EU314721 & & & SPPV & Makhdoom-2007 & 2007 & India \\
\hline AY368684 & & KF495237 & SPPV & Rumanian Fanar & NI & India \\
\hline KF661974 & & & SPPV & GanSuGT/11/2012 & 2012 & China \\
\hline KJ026555 & & & SPPV & $\mathrm{Lx} / \mathrm{Gs}$ & 2010 & China \\
\hline KC847056 & & & SPPV & Zabaikalsk & 2010 & Russia \\
\hline AF124516 & & & LSDV & Neethling & NI & South Africa \\
\hline KX960780 & & & LSDV & LSDV-WA-3 & NI & Iran \\
\hline KP702291 & & & GTPV & Jammu and Kashmir & 2013 & India \\
\hline KF468757 & & & GTPV & JK/goat/27 & 2013 & India \\
\hline FJ748488 & & & GTPV & Akola/Maharashtra & 2008 & India \\
\hline AY773088 & & & GTPV & Liujiang/2003 & 2003 & China \\
\hline JN596275 & & JQ310672 & GTPV & GTPV/HuB/2009 & 2009 & China \\
\hline HM572329 & & & GTPV & GPV/ChongQ/2009 & 2009 & China \\
\hline \multirow[t]{13}{*}{ EF514892 } & & & GTPV & Xinjiang & NI & China \\
\hline & & KF495245 & GTPV & Mukteswar/1964 & 1946 & India \\
\hline & & FJ869390 & SPPV & SPPV24 & 1984 & Oman \\
\hline & & FJ869355 & GTPV & Bangladesh/86 & 1986 & Bangladesh \\
\hline & & FJ869356 & GTPV & Turkey/98 Denizli & 1998 & Turkey \\
\hline & & FJ869361 & GTPV & GTPV15 & NI & Sudan \\
\hline & & KF495240 & SPPV & Maharashtra/25 & 2004 & India \\
\hline & & FJ869387 & SPPV & Nigeria/77 & 1977 & Nigeria \\
\hline & & FJ869345 & SPPV & Tunisia/01 13P2 & 2001 & Tunisia \\
\hline & & KF661976 & SPPV & GanSuHN/12/2012 & 2012 & China \\
\hline & & FJ869376 & LSDV & RSA/54 Haden & 1954 & South Africa \\
\hline & & KP071936 & LSDV & Egy & 2011 & Egypt \\
\hline & & KP663706 & LSDV & Mojo/B01/2011 & 2011 & Ethiopia \\
\hline
\end{tabular}




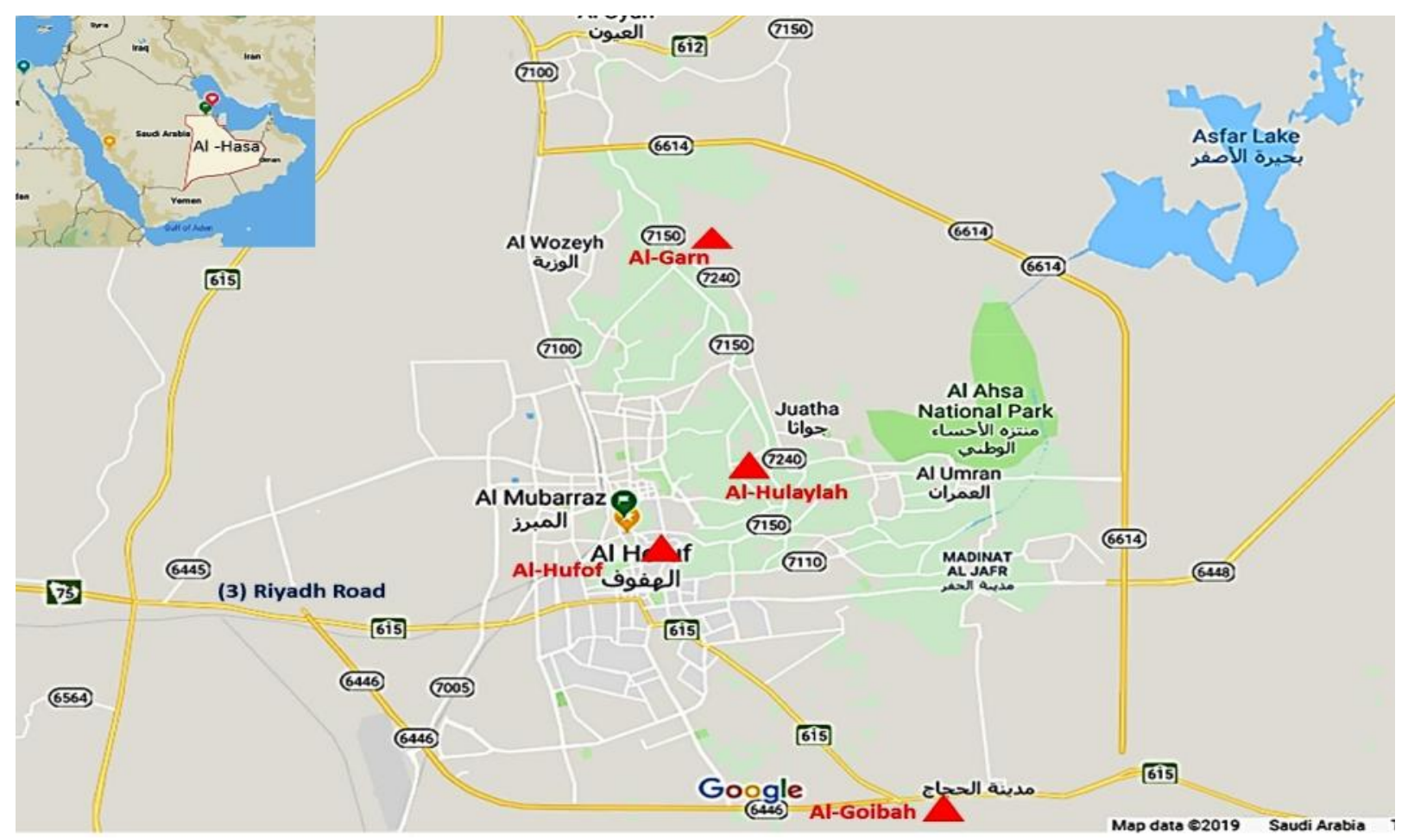

Fig 1. Geographical map of Al-Hassa Governorate in the Eastern Province of Saudi Arabia. Red triangle showing the location SPPV and GTPV outbreaks.

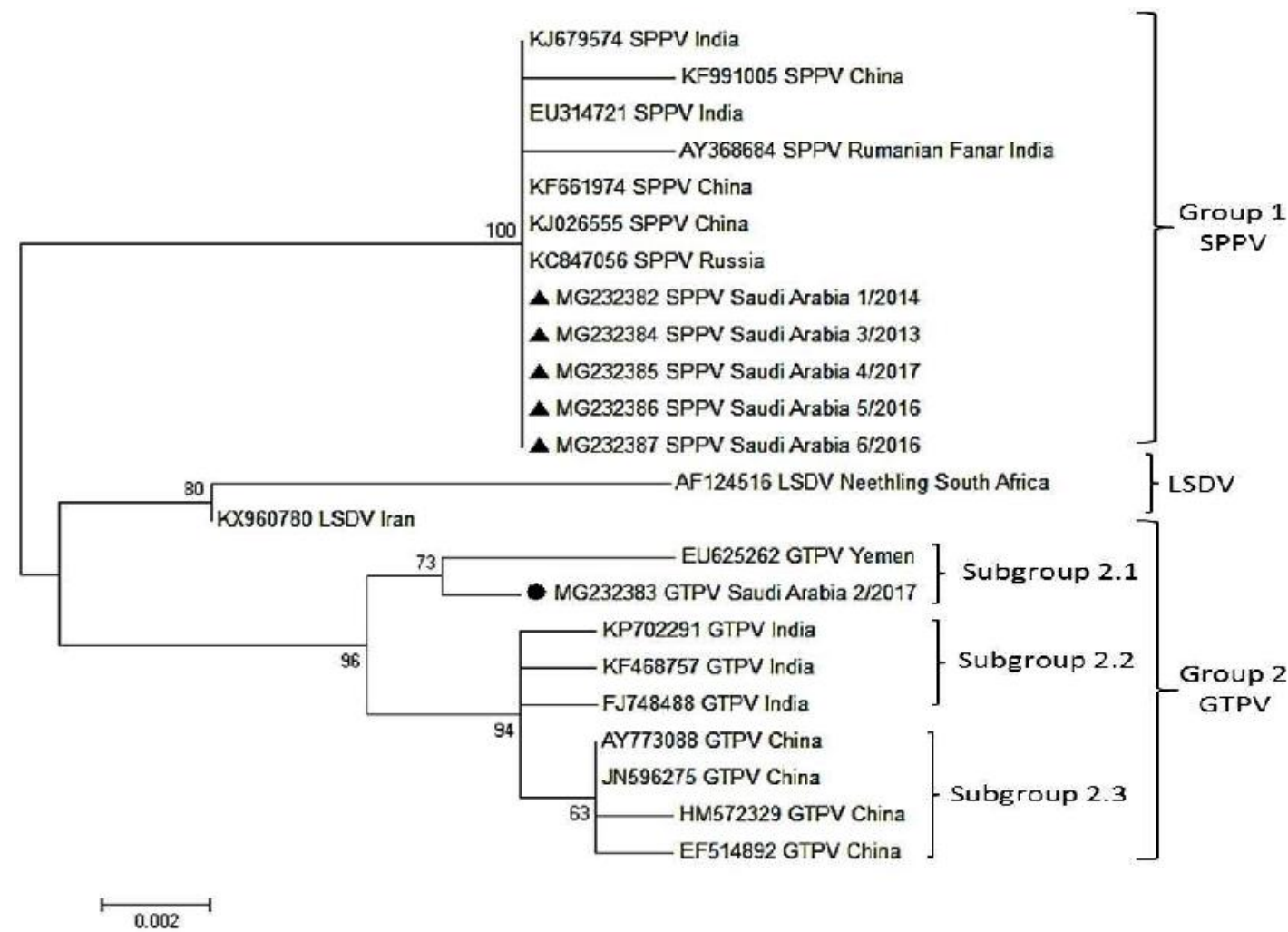

Fig 2. Phylogenetic analysis of different capripoxviruses based on the full nucleotide sequence of $P 32$ gene. Phylogenetic tree was constructed by neighbor-joining method using MEGA 5.2 software and the reliability of the tree was tested by bootstrapping with 1000 replicates. 


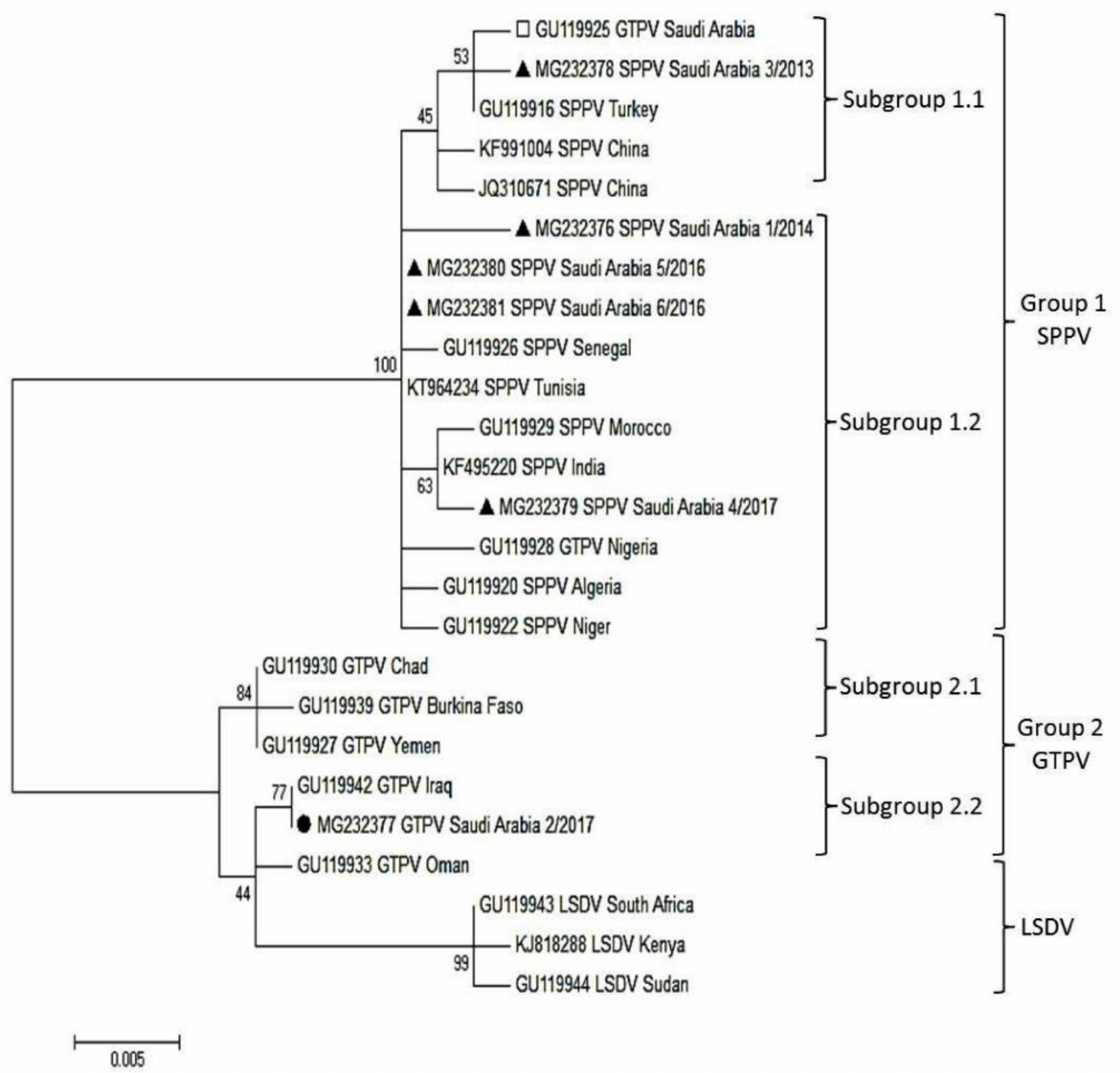

Fig 3. Phylogenetic analysis of different capripoxviruses based on the full nucleotide sequence of PRO30 gene. Phylogenetic tree was constructed by neighbor-joining method using MEGA 5.2 software and the reliability of the tree was tested by bootstrapping with 1000 replicates. 


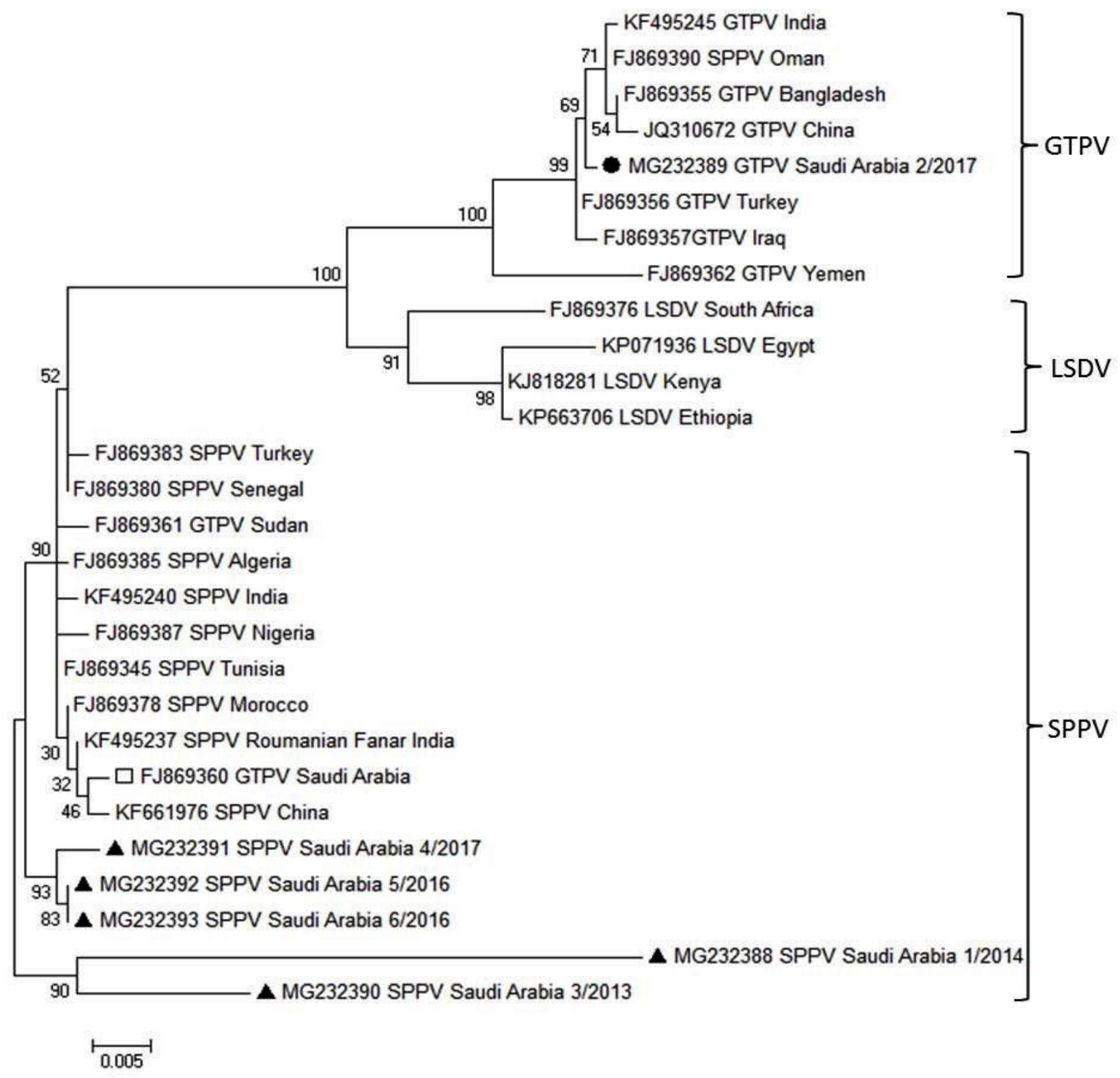

Fig 4. Phylogenetic analysis of different capripoxviruses based on the full nucleotide sequence of GPCR gene. Phylogenetic tree was constructed by neighbor-joining method using MEGA 5.2 software and the reliability of the tree was tested by bootstrapping with 1000 replicates.

\section{DISCUSSION}

SPPV and GTPV diseases are endemic in several regions worldwide. They are listed as class A animal diseases due to the fact that they reduce the productive potential and limit the development of the intensive feedlot system of the sheep and goat industries (OIE, 2010). In the present study, six field strains of SPPV and GTPV were identified from six different outbreaks in Al-Hassa in the Eastern Province of Saudi Arabia. All cases showed signs of pyrexia and skin lesions such as macules and papules. Multifocal necrotic lesions were observed in the lungs of some of the animals that had died. The majority of CaPV strains are hostspecific, and, therefore, the distinguishing of $\mathrm{CaPV}$ strains is based on the animal species from which the viruses were taken. However, this classification method is erroneous (Babiuk et al., 2009; Bhanuprakash et al., 2010; Yan et al., 2012). The conventional serological assays successfully detect and confirm the presence of the $\mathrm{CaPV}$ antigen, but they are unable to differentiate between SPPV and GTPV. For this reason PCR is the most frequently used technique for identification. In this study, we used the multiplex PCR for the detection of 
$\mathrm{CaPVs}$ and then analyzed the complete open reading frames of the P32, PRO30 and GPCR genes of the six detected field strains by comparing them with other $\mathrm{CaPVs}$ worldwide. Alignment analysis and construction of the phylogenetic trees of the three genes revealed that the six detected CaPVs were classified as five SPPVs and one GTPV consistently according to their host species (Figs 2, 3 and 4).

Based on phylogenetic analysis of the P32 gene, the six Saudi Arabia strains were clustered into two separate groups (Fig 2). In the SPPV group (group 1), five Saudi Arabia strains were clustered with SPPV isolates from Russia, India and China. It is obvious that because they clustered together, the five Saudi Arabia SPPVs are closely related to each other. The GTPV group (group 2) was divided into three subgroups based on the geographical distribution of the isolates. The GTPV/Saudi Arabia 2/2017 strain is closely related to and clustered with the Sana'a/1983 strain of GTPV from Yemen in subgroup 2.1. The Indian strains formed subgroup 2.2, whereas the Chinese strains formed subgroup 2.3.

Based on phylogenetic analysis of the PRO30 gene, the six detected Saudi Arabia strains were clustered into two separate groups: SPPVs and GTPVs (Fig 3). In group 1 (SPPVs), the five SPPV Saudi Arabia strains were divided, along with different worldwide SPPVs, into two subgroups based on their geographical location and year of collection. SPPV/Saudi Arabia 3/2013 is closely related to GTPV/Saudi Arabia/1993, which is considered an SPPV, and clustered with SPPV strains from Turkey and China as subgroup 1.1. Subgroup 1.2 contains the Saudi strains collected during 2014, 2016 and 2017 and is clustered together with SPPV strains from African countries (Senegal, Tunisia, Morocco, Algeria and Niger) and India. Interestingly, GTPV/Saudi Arabia/1993 and GTPV/Nigeria are clustered in the SPPV group, a finding that agrees with the study of Lamien et al., 2011a. Group 2 (GTPV) was divided into two subgroups. GTPV/Saudi Arabia 2/2017 is closely related to the GTPV from Iraq and clustered with it and the GTPV from Oman in subgroup 2.2. The Sana a/1983 strain of GTPV from Yemen is clustered with GTPVs from the African countries of Chad and Burkina Faso in subgroup 2.1.

Alignment and phylogenetic analysis of the GPCR gene showed that the six detected Saudi Arabia strains were clustered into two separate groups: SPPVs and GTPVs (Fig 4). SPPV/Saudi Arabia 3/2013 is closely related to SPPV/Saudi Arabia 1/2014, whereas SPPV/Saudi Arabia 4/2017, SPPV/Saudi Arabia 5/2016 and SPPV/Saudi Arabia 6/2016 are closely related to each other. GTPV Saudi Arabia 2/2017 is clustered with GTPVs from India, China and Bangladesh in the GTPV group. Interestingly, GTPV/Saudi Arabia/1993 and the GTPVs from Sudan and Oman are clustered outside the group, corresponding with their host of origin (Le Goff et al., 2009). Although the sequence analysis of the three genes (P32, RPO30 and GPCR) could be used to discriminate the SPPV, GTPV and LSDV strains, it is not known whether the data they contain can show the host specificity of the viruses. This study is the first one to investigate the genetic relatedness among SPPV and GTPV strains based on full nucleotide sequences of the $P 32, P R O 30$ and GPCR genes in Saudi Arabia. Further work will be carried out on the deduced amino acid residues of these genes.

In conclusion, the six detected Saudi Arabia strains were segregated into SPPV and GTPV groups dependably in the three constructed phylogenetic trees. The alignment and phylogenetic tree of one gene alone is not enough to investigate the genetic relationship of CaPVs. Multiple genetic sequencing studies and alignments will greatly improve the accuracy of the diagnosis of the pox diseases and contribute to the $\mathrm{CaPV}$ epidemiology and control of the diseases in Saudi Arabia. Understanding the P32, PRO30 and GPCR genes will be helpful in identifying the origins of $\mathrm{CaPV}$ epidemics and will make it possible to control and prevent $\mathrm{CaPV}$ infections.

Acknowledgments: The authors acknowledge the Deanship of Scientific Research at King Faisal University for the financial support under the annual research project [Grant No. 170012].

\section{REFERENCES}

Abu-Elzein, A., F. M. Houwsawi, O. Ramdan, A. Gameel, A. Alafalq and O. Algunde (2003). Observations on natural and experimental infection in sheep and goat with a virulent field a capripoxvirus with high affinity to goats. Veterinarski arhiv 73:119-131.

Al- Shabebi, A. A., I. M. El-Sabagh, E. M. Abu-Elzein, A. A. Zaghawa, A. A. Al-Naeem and F. M. Housawi (2014). Molecular detection and phylogenetic analysis of sheeppox virus in AlHassa of Eastern Province of Saudi Arabia. Advances in Animal and Veterinary Sciences, Special Issue 2, Advances in Diagnosis and Control of Infectious Diseases of Animals 3134.

Babiuk, S., T. R. Bowden, G. Parkyn, B. Dalman, D. M. Hoa, N. T. Long, P.P. Vu, X. Bieu do, J. Copps and D. B. Boyle (2009). Yemen and Vietnam capripoxviruses demonstrate a distinct host preference for goats compared with sheep. J Gen Virol 90: 105-114.

Beard, P. M., S. Sugar, E. Bazarragchaa, U. Gerelmaa, S. H. Tserendorj, E. Tuppurainen and R. Sodnomdarjaa (2010). A description of two 
outbreaks of capripoxvirus disease in Mongolia. Vet Microbiol 142: 427-431.

Bhanot, V., V. Balamurugan, V. Bhanuprakash, G. Venkatesan, A. Sen, V. Yadav, R. Yogisharadhya and R. K. Singh (2009). Expression of P32 protein of goatpox virus in Pichia pastoris and its potential use as a diagnostic antigen in ELISA. J Virol 162: 251257.

Bhanuprakash, V., B. K. Indrani, M. Hosamani and R. K. Singh (2006). The Current Status of sheep pox disease. Comp Immunol Microbiol Infect Dis 29: 27-60.

Bhanuprakash, V., G. Venkatesan, V. Balamurugan, M. Hosamani, R. Yogisharadhya, R. S. Chauhan, A. Pande, B. Mondal and R.K. Singh (2010). Pox outbreaks in sheep and goats at Makhdoom (Uttar Pradesh). India: evidence of Sheeppox virus infection in goats. Transbound Emerg Dis 57: 375-382.

Cao, J. X., P. D. Gershon and D. N. Black (1995). Sequence analysis of HindIII Q2 fragment of capripoxvirus reveals a putative gene encoding a G-protein-coupled chemokine receptor homologue. Virology 209(1): 207-212.

Hamouda, M., F. Al-Hizab and I. M. El-Sabagh (2017). Clinical, pathological and molecular diagnosis of sheeppox virus in Saudi Arabia. J Anim Plant Sci 27(1): 91-97.

Heine, H. G., M. P. Stevens, A. J. Foord and D. B. Boyle (1999). A capripox virus detection PCR and antibody ELISA based on the major antigen P32 the homolog of the vaccinia virus H3L gene. J Immunol Methods 227: 187-96

Hosamani, M., B. Mondal, P. A. Tembhurne, S. K. Bandyopadhyay, R. K. Singh and T. J. Rasool (2004). Differentiation of sheep pox and goat poxviruses by sequence analysis and PCR-RFLP of P32 gene. Virus Genes 29: 73-80.

Lamien, C. E., C. Le Goff, R. Silber, D. B. Wallace, V. Gulyaz, E. Tuppurainen, H. Madani, P. Caufour, T. Adami, M. El Harrak, A. G. Luckins, E. Albina and A. Diallo (2011a). Use of the Capripoxvirus homologue of Vaccinia virus 30 $\mathrm{kDa}$ RNA polymerase subunit (RPO30) gene as a novel diagnostic and genotyping target: development of a classical PCR method to differentiate Goat poxvirus from Sheep poxvirus. Vet Microbiol 149: 30-39.

Lamien, C. E., M. Lelenta, W. Goger, R. Silber, E. Tuppurainen , M. Matijevic , A. G. Luckins and A. Diallo (2011b). Real time PCR method for simultaneous detection, quantitation and differentiation of capripoxviruses. $\mathrm{J}$ Virol Methods 171: 134-140.
Le Goff, C., C. E. Lamien, E. Fakhfakh, A. Chadeyras, E. Aba-Adulugba, G. Libeau, E. Tuppurainen, D. B. Wallace, T. Adam, R. Silber, V. Gulyaz, H. Madani, P. Philippe Caufour, S. Hammami, A. Diallo and E. Albina (2009). Capripoxvirus G-protein-coupled chemokine receptor: a hostrange gene suitable for virus animal origin discrimination. J Gen Virol 90: 1967-1977.

Mangana-Vougiouka, O., P. Markoulatos, G. Koptopoulos, K. Nomikou, N. Bakandritsos and O. Papadopoulos (2000). Sheep poxvirus identification from clinical specimens by PCR, cell culture, immunofluorescence and agar gel immunoprecipitation assay. Mol Cell Probes 14(5): 305-310.

OIE, (2010). Sheep Pox and Goat Pox. Manual of Diagnostic Tests and Vaccines for Terrestrial Animals. Chapter 2.7.14.1-12, Online:http://www.oie.int./fileadmin/Home/eng/ Health_standards/tahm/2.07.14_S_Pox_G_ROX .Pdf

Rao, T. V. S. and S. K. Bandyopadhyay (2000). A comprehensive review of goat pox and sheep pox and their diagnosis. Anim Health Res Rev 1(2): 127-36.

Su, H. L., H. J. Jia, C. Yin, Z. Z. Jig, X. N. Luo and Y. X. Chen (2015). Phylogenetic analysis of Gansu sheeppox virus isolates based on P32, GPCR and PRO30 genes. Genet Mol Res 14 (1): 1887 1898.

Tian, H., Y. Chen, J. Wu, Y. Shang and X. Liu (2010): Serodiagnosis of sheeppox and goatpox using an indirect ELISA based on synthetic peptide targeting for the major antigen P32. Virol J 7(1): 245- 248.

Tulman, E. R., C. L. Afonso, Z. Lu, L. Zsak, J. H. Sur, N. T. Sandybaev, U. Z. Kerebekova, V. L. Zaitsev, J. F. Kutish and D. L. Rock (2002). The genomes of sheeppox and goatpox viruses. J Virol 76: 6054-6061.

Yan, X. M., Y. F. Chu, G. H. Wu, Z. X. Zhao, J. Li, H. X. Zhu and Q. Zhang (2012). An outbreak of sheep pox associated with goat poxvirus in Gansu Province of China. Vet Microbiol 156: 425-428.

Zheng, M., Q. Liu, N. Jin, J. Guo, X. Huang, H. Li, W. Zhu and Y. Xiong (2007). A duplex PCR assay for simultaneous detection and differentiation of Capripoxvirus and Orf virus. Mol Cell Probes 21: 276-281.

Zhou, T., H. Jia, G. Chen, X. He, Y. Fang, X. Wang, Q. Guan, S. Zeng, Q. Cui and Z. Jing (2012). Phylogenetic analysis of Chinese sheeppox and goatpox virus isolates. Virol J 9: 25- 32. 